Case Report

\title{
Osteoid Osteoma of the Ankle Posing As a Distal Tibiofibular Syndesmosis: A Rare Case Report
}

\author{
Anand Kumar S. ${ }^{1}$, Arjun Ballal ${ }^{2}$, Anoop Hegde ${ }^{3} \&$ A. Ponnambalam ${ }^{4}$ \\ ${ }^{1}$ Chief consultant and senior surgeon, ${ }^{2,3}$ Registrar Department of Orthopaedics, \\ ${ }^{4}$ Chief Anaesthesio logist and Intensivist, Department of Anaesthesiology, ARShospital, Tirupur. \\ *Corresponding Author : Arjun Ballal, C/O ARS Hospital, 6/53,6 ${ }^{\text {th }}$ street Thennampalyam Extension, Palladam Road, Tirupur - 641604 , \\ Tamil Nadu, Mobile: +91 7708913999 E-mail : 5arjunballal@gmail.com
}

Received

: 14-10-2015

Review Completed : 27-02-2016

Accepted

:08-03-2016

Keywords : Osteoid osteoma, syndesmosis, exostosis, osteoblastic, subperiosteal

\begin{tabular}{|c|}
\hline Access this article online \\
\hline Quick Response Code \\
\hline
\end{tabular}

\section{Abstract :}

Osteoid osteoma is a benign tumor of the bones. The adolescent males are the most commonly involved population. Pain of the affected site forms the common symptom during clinical presentation. The lower limbsare the most commonly affected site.

We present here a case report of a middle aged gentleman who presented to us with complaints of pain and mass over the non-dominant ankle for four years. Clinical examination revealed a bony hard swelling proximal to the lateral malleolus. The radiographs and CT scan reports were consistent with features suggestive of an exostosis bridging the distal tibio-fibular syndesmosis. Surgical exploration revealed a mass with definite borders bridging the distal tibio-fibular syndesmosis. Excision biopsy was performed and the histopathology of the specimen reported features consistent with that of an osteoid osteoma. The patient was started on physiotherapy of the ankle and he was noted to have full range of ankle motion at six months. As no such case has been reported in earlier in literature we present it as a rare case report.

\section{Introduction}

Osteoid osteomas are tumors of the bone which have lower limbs as the commonest site of involvement [1]. These tumors were first described in 1936 by Jaffe [1]. The tumor is described to be osteoblastic and benign [1]. Adoloscent young males are the commonly affected population [1]. The classical presentation is only noted in two-third of the patients [2].Radiographic appearance of a radioluscent central nidus with surrounding area of cortical thickening is considered a hallmark for making a diagnosis of osteoid osteoma[1,3]. The tumor has a subperiostealpresentation [4]. Several studies and reports have suggested that the tumor has a subperiosteal presentation to begin with and later becomes cortical or intramedullary [4].

\section{Case report}

A 35 year old gentleman presented to us with complaints of pain and a mass over the left ankle for five years. There was no preceeding history of trauma or fall. The mass had an insidious onset and had a progressive growth. The pain was continuous and had a progressive course. There was no associated history of fever, weight and appetite loss or any other medical complaints. He had no history of medical comorbidities of Diabetes M ellitus, hypertension etc.

Clinical evaluation of the mass revealed a bony hard mass measuring $4 \times 3 \mathrm{cms}$ with definite borders, one $\mathrm{cm}$ proximal to the lateral malleolus (Figure 1). No instability or restriction of ankle range of motion was noted when compared to the normal ankle. The skin over the mass was smooth with no signs of inflammation or dilated veins. No other similar swellings were noted in the rest of the body. Examination of all systems was normal. Radiographs revealed a central radiolucent nidus with surrounding area of cortical thickening(Figure 2). Computed tomography reported a large neck wide osseus lesion arising from the lateral cortex of the distal tibia extending and uniting with 
the medial fibular cortex forming an intramedullary bony bar which resembled a picture of an exostosis (Figure 3).

After the physician and anaesthesia fitness was attained he was taken up for surgical excision of the mass. A lateral approach to the ankle was employed for exposure of the mass. The swelling was noted to measuring $4 \times 3 \mathrm{cms}$ in size (Figure 4). Excision of the mass was done and the specimen was forwarded to the pathologist for histopathological analysis. A small bony bridge was retained to maintain the tibio-fibular syndesmosis (Figure 5). Macroscopically, the swelling was completely bony with no cartilage(Figure 6). Post-operatively a below knee slab was applied for a period of sixweeks.

The histopathology reported the presence of a central nidus surrounded by irregular osteoid tissues which were present in the highly vascular stroma of connective tissue containing osteoblastic cells. Presence of 'lace like osteoid and calcified matrix lined by osteoblasts and osteoclasts with a well vascularised stroma' was conclusive of an osteoid osteoma. He was started on ankle rehabilitation

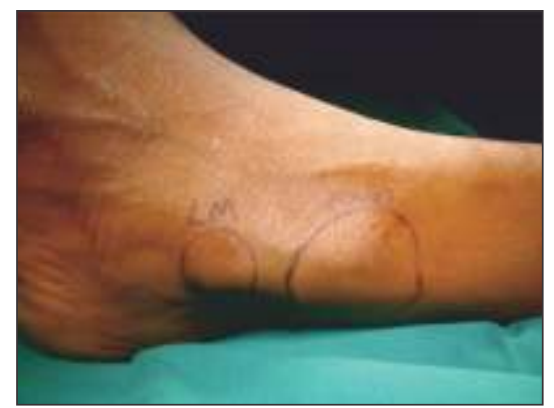

Figure 1: The mass being demarcated by the larger circle

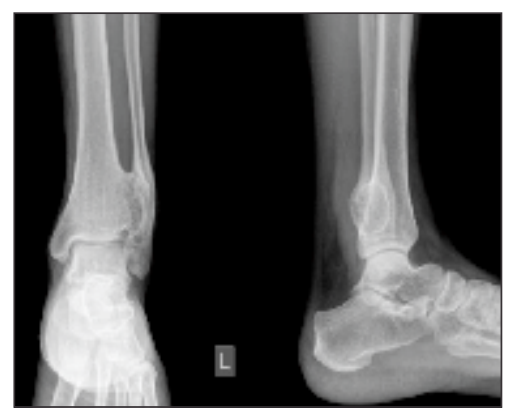

Figure 2: Plain x-rays anteroposterior and lateral views of the left ankle showing a globular mass encroaching on the distal tibiofibular syndesmosis bridging the distal tibiofibular joint. Note globular mass with well demarcated margins and central radioluscentnidus.

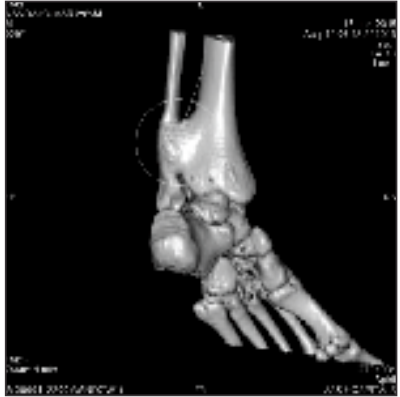

Figure 3 : CT images with 3-dimension reconstruction showing a bony mass bridging the distal tibio-fibular syndesmosis ( $\mathrm{M}$ arked byarrow).

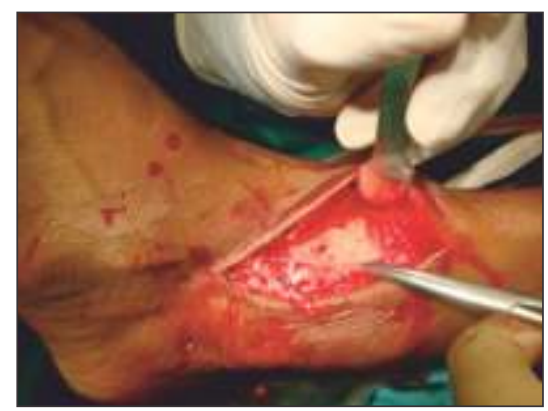

Figure 4: Intraoperatively the lesion was globular with well demarcated margins. Note the artery forceps pointing the lesion.

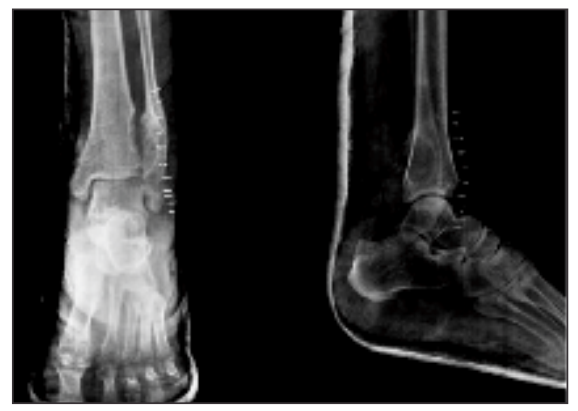

Figure 5 : Post-operative radiographs antero-posterior and lateral views showing post resection picture of the left ankle. Note the small bony bridge which was retained for maintaining the distal tibiofibular syndesmosis.

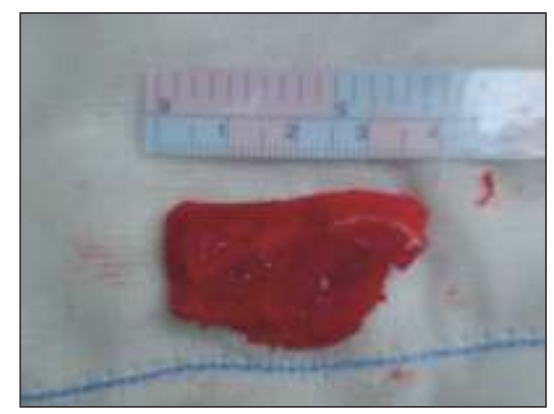

Figure 6: $4 \times 3 \mathrm{~cm}$ mass resected, which was bony with no cartilage. 
and physiotherapy at 6 weeks. During the final review at six months he was noted to have satisfactory ankle function with no complications.

\section{Discussion}

Osteoid osteomas may be intra-cortical, subperiosteal, endosyeal or intra-medullary in location. Presence of area of sclerosis around the lucent area, due to reactive bone formation is typical of osteoid osteoma[3]. The nidus is better demonstrated in a CT scan than in an M RI[1,3].A mature nidusmay be radio dense due to mineralization. CT scan demonstrates a nidus which is a well-defined area of low attenuation which is surrounded by an area of high attenuation of reactive sclerosis [1].

A series by Davidson and colleagues reported a delay in six months in making a diagnosis of osteoid osteoma because of the atypical radiographic appearance [2]. They also reported that the diagnosis could be delayed upto two years[2].

\section{References}

1. Erol B, Pill SG, Meyer JS, et al.: Limping in a 12-year old boy. ClinOrthopRel Res 2002, 403:281-289.

2. Davidson RS, Mahbouri S, Heyman S, et al.: Nondiaphyseal osteoid osteomas in the pediatric patient. ClinOrthopRelat Res 1989:230-234.

3. Goswami P, Medhi N, Sarma PK, et al.: Imaging features of osteoid osteoma in plain radiograph, CT and M R: A case report and review of literature. Ind J Radio Imag2005, 15:481-484.

4. Kayser F, Resnick D, Haghighi P, et al.: Evidence of the subperiosteal origin of osteoid osteoma in tubular bones: Analysis of CT and MR imaging. Am J Roentgenol1998, 170:609614.

5. Mommert I, Heuschmidt M, Suckel A.Intraarticular osteoid osteoma as a cause of chronic ankle pain. Orthopade. $2009 \mathrm{M}$ ar; 38(3):269-73.

6. Temple HT, Vinh TN, Mizel M. Intra-articular osteoid osteoma as a cause of chronic ankle pain. Foot Ankle Int. 1998 Jun; 19(6):384-7.

7. SS Suresh and V Rani: Atypical periosteal osteoid osteoma: a case report. Cases Journal 2009, 2:124
Mommert and colleagues reported in their literature about intra-articular osteoid osteomas causing chronic ankle pain. They concluded that occurance of the tumor in an intra-articular location was rare and did present with non-specific symptoms and radiographic signs which could prolong the diagnosis. Complete en-bloc resection of the tumor brought about an improvement of symptoms [5].

Temple HT and colleagues also presented a series of patients diagnosed with intra-articular osteoid osteoma who presented with chronic ankle pain [6].

Osteoid osteomas tend to regress over a period of time even without treatment [7]. Salicylates may accelerate the healing in osteoid osteoma and is a good diagnostic and therapeutic consideration [1].

The standard treatment of osteoidosteoma is enbloc resection, though other modalities of treatment including radio ablation have been practiced [1]. 